\title{
The Role of Grit Among Polish EFL Majors: A Comparative Study of 1st-, 2nd-, and 3rd-Year University Students
}

\author{
Joanna Zawodniak, University of Zielona Góra \\ iD https://orcid.org/0000-0002-3219-145X \\ j.zawodniak@in.uz.zgora.pl
}

Mirosław Pawlak, Adam Mickiewicz University \& State University of Applied Sciences in Konin

https://orcid.org/0000-0001-7448-355X

pawlakmi@amu.edu.pl

Mariusz Kruk, University of Zielona Góra

iD https://orcid.org/0000-0001-5297-1966

mkruk@uz.zgora.pl

\begin{abstract}
The foreign and second language (L2) learning process is shaped by a constellation of individual difference (ID) factors, some of which (e.g., age, anxiety, motivation, aptitude, learning styles, language learning strategies) have long been investigated by specialists, whereas others have only recently attracted their attention. One of such underexplored variables is grit, usually referred to as a personality trait predictive of success and supportive of various important skills including, among others, cooperation and creative thinking. Given the vital role that this ID factor might play in the L2 classroom, the present paper reports a mixed-methods study which addressed the following issues: (1) the level of grit experienced by 99 Polish university BA students majoring in English, (2) the differences in this respect between 1st-, 2nd- and 3rd-year students, and (3) possible manifestations and dynamics of grit in learning English as a foreign language (EFL). Grit was measured using the Polish version of Teimouri et al.'s (2020) language-specific grit scale and a semi-structured interview. One-way ANOVA was employed to quantitatively compare the means of the respondents enrolled in different levels of a BA program, whereas a four-stage procedure (Dörnyei, 2007) was adopted to analyze the qualitative data. The results demonstrated a relatively high level of grit among all the respondents and statistically significant differences for one of its components, that is, consistency of interest in learning the target language between 1st- and 2nd- as well as 1st- and 3rd-year students. This particular subconstruct of grit was found to be mediated by such factors as learning styles and strategies, emotions, weariness or personality. In addition, grit was shown to be linked to participants' identification of their L2 learning weaknesses and the ability to eliminate them.
\end{abstract}

Keywords: grit, domain-general grit, L2 grit, perseverance of effort, consistency of interest

This work is licensed under the Creative Commons Attribution-ShareAlike 4.0

International agreement (CC BY-SA 4.0).

http://creativecommons.org/licenses/by-sa/4.0/
Journal for the Psychology of Language Learning

ISSN: 2642-7001

(2021) Volume 3, Issue 2, pp. 118-132 https://doi.org/10.52598/jpl1/3/2/8 


\section{INTRODUCTION}

Over the past decade, there has been a shift in interest in the field of second language acquisition (SLA) from the routinely investigated individual difference (ID) factors, such as motivation, anxiety or aptitude (Li, 2016; Masgoret \& Gardner, 2003; Pawlak, 2017, 2020), to personality traits and their place in foreign/second language learning (Dörnyei \& Ryan, 2015). Fascinated by the principles of positive psychology (Seligman, 2003; Seligman \& Csikszentmihalyi, 2000), applied linguists have started investigating connections between students' personality and optimal functioning as L2 users (Dewaele, 2014; Dewaele \& MacIntyre, 2016; MacIntyre \& Gregersen, 2012; MacIntyre et al., 2016; Oxford, 2015). In fact, personality traits were found to occupy an important position in SLA, but primary reliance on domain-general data-collection tools resulted in equivocal and contradictory findings, which prompted specialists to search for valid and reliable language-domain research instruments (Teimouri et al., 2020).

One of the much-discussed non-cognitive ID variables that has recently garnered ample, albeit still insufficient, attention is grit, understood as hardiness of character and perseverance (Duckworth et al., 2007) that can enhance a number of crucial skills, including cooperation, creative thinking, engagement in the learning process and the ability to cope with adverse circumstances in both academic and vocational settings (Heckman \& Mosso, 2014; Roberts, 2009). Concurrently and to a certain extent in response to related research, many educators have come to believe that encouraging the development of grit could help their students unleash their full, though frequently dormant, potential in various paths of life (cf. Shechtman et al., 2013; Tough, 2011, 2012). Not surprisingly, grit is perceived to be a fundamental variable in L2 learning, which is a particularly stressful and challenging endeavor that requires almost an endless reservoir of stamina and dedication to extended study regardless of how difficult or discouraging this process may turn out to be (Dörnyei, 2005; Hakuta et al., 2000; Horwitz, 2001; Horwitz et al., 1986; Pawlak, 2011). In view of its immediate relevance to SLA, where it has been found to be one more predictor of successful performance and achievement in L2 learning (Keegan, 2017; Khajavy et al., 2020; Teimouri et al., 2020; Yamashita, 2018), grit deserves a more systematic, domain-specific approach. This is the rationale behind the present paper which reports a study that was aimed at comparative examination of this ID factor among 1st-, 2nd- and 3rd-year university students in Poland majoring in English, focusing on its intensity, dynamics and manifestations..

\section{LITERATURE REVIEW}

\section{Domain-General Grit}

The concept of grit has its origins in the field of social psychology, where it was defined by Duckworth et al. (2007, p. 1087) as "perseverance and passion for long-term goals," standing for an individual's tendency to tenaciously confront challenges, difficulties and setbacks together with readiness to maintain effort and interest over an extended period of time. This is why Duckworth et al. (2007) refer to gritty individuals' attempts to reach higher attainment as a marathon which they are determined to run even when faced with disappointments or failures. What pushes them towards executing their plans is the interplay of volitional strength and motivation to succeed (Changlek \& Palanukulwong, 2015; Dweck, 2006), which had already been highlighted around a century ago by various British and American psychologists asserting that cognitive ability is not the most important predictor of lifetime achievement. To begin with, James (1907) pointed out that the inability or unwillingness to persist in doing things despite temporary obstacles can cause individuals to take advantage of no more than a small portion of their mental resources. At the same time, Galton's (1892) and Cox's (1926) studies of the biographies of distinguished figures in various disciplines and areas of activity (e.g., scientists, judges, statesmen, artists, athletes) indicated that their outstanding accomplishments stemmed from a combination of ability, zeal, mental power and capacity for hard work. More specifically, those individuals' high achievement was found to be predicted by exceptional, long-term commitment to their goals, firmness of character, sustained motivation and effort and, last but not least, a belief in their own potential (cf. Ericsson \& Charness, 1994; Howe, 1999).

Duckworth et al. (2007) discussed grit as a higher-order construct composed of two lower-order components, such as perseverance of effort $(\mathrm{PE})$, that is, commitment towards the accomplishment of one's long-term goals, and consistency of interest (CI), that is, the ability to maintain one's interest in the face of obstacles and problematic 
situations. Understood in this way, grit has been shown to be a core contributor to success and performance across a variety of life contexts. This was possible thanks to the two grit domain-general scales developed, validated and used by Duckworth et al. (2007) as well as Duckworth and Quinn (2009), and then applied to diverse settings (i.e., social, educational, commercial, military) by other scholars (e.g., Eskreis-Winkler et al., 2014; Georgoulas-Sherry \& Kelly, 2019; Wolters \& Hussain; 2015). The first of these scales, known as the Grit Scale (Grit-O, Duckworth et al., 2007), is a self-report tool consisting of twelve Likert-scale items intended to measure perseverance of effort (6 items) and consistency of interest (6 items). The second, referred to as the Grit Scale (Grit-S) (Duckworth \& Quinn, 2009), is a shortened version of the Grit-O, comprised of eight items, four tapping into each of the two subconstructs of this personality trait. The use of these scales has enabled researchers to uncover the predictive value of grit in different spheres of life. For example, Duckworth et al. (2007) provided evidence of this predictive power by showing that the attainment of ambitious goals is positively correlated not only to a person's ability but also to his or her endurance while performing challenging tasks and that grit tends to increase with age. More specifically, grittier individuals were reported to reach higher levels of education, score higher in the Scripps National Spelling Bee, make fewer career transitions and gain higher GPA than their less gritty counterparts. It should also be stressed at this juncture that perseverance of effort was a superior contributor to GPA, while consistency of interest turned out to be a more pronounced indicator of career switches and Scripps National Spelling Bee outcomes (cf. Duckworth et al., 2011; Duckworth \& Quinn, 2009). Also, grit was shown to be a better indicator of lower drop-out rates at the military academy than self-control and a summary measure of cadet quality used by the admissions committee (cf. EskreisWinkler et al., 2014). In addition, this ID factor turned out to be positively linked to well-being and behavioral/emotional engagement (Datu et al., 2016; Von Culin et al., 2014), emotional stability (Credé et al., 2017 ) and marriage duration. By contrast, it was revealed to be unconnected to one's cognitive ability, academic status, race or gender (Credé et al., 2017), physical health, and general intelligence (Eskreis-Winkler et al., 2014).

Without downplaying the significance of grit as the ability to capitalize on stamina and dedication in the course of pursuing long-term goals, it is warranted at this point to address some controversies concerning the structure of this ID factor and its relationship with other trait-like variables. A good point of reference for this purpose is Credé et al.'s (2017) meta-analytic examination of grit that questions, among other things, its hierarchical structure. To be more specific, while this ID factor is on the whole related to general academic performance, such performance is much more strongly associated with PE than with CI, which casts doubt on the understanding of the essence of grit. To put it simply, this may mean that individuals who score higher on $\mathrm{PE}$ are grittier and more likely to become high-achievers than those who manifest greater CI. Another area of inconsistency is that the proposed structure of grit can be perceived as not equally applicable to different social contexts and populations, as is the case, for instance, with the Philippine and Korean collectivist communities which were reported to be more PE- than CI-oriented (Datu et al., 2016; Hwang et al., 2017). While presenting the criticisms of grit, it should be added that the last few decades have witnessed numerous studies of different constructs that can be described in terms of perseverance and consistency, such as, for instance, persistence, industriousness, self-control, resilience as well as conscientiousness as a component of the Big Five model of personality (e.g., Costa, \& McCrae, 1992; De Fruyt et al., 2000; Eisenberger, 1992; PerkinsGough, 2013; Roberts et al., 2005). Since all such constructs display conceptual similarities with grit, examining this factor without formally establishing its discriminant validity in relation to those variables by means of methodologies commonly used for this purpose (e.g., confirmatory factor analyses) poses the risk of repackaging them under a new label (Credé, 2018).

Objections of this kind notwithstanding, the ability to endure in the pursuit of long-term, challenging goals in the face of possible pitfalls and difficulties, as well as to maintain interest in the accomplishment of these goals is instrumental in successful functioning in the modern world, and as such certainly involves language learning contexts. The evidence for the growing interest in the role of grit in human life is its inclusion in various character development programs and teaching materials, as is the case with American mainstream educators engaged in developing it together with other positive qualities such as, for example, social intelligence, gratitude or curiosity (Shechtman et al., 2013: Tough, 2011; Zernike, 2016). It also certainly makes 
sense to examine the role of grit in the lengthy and arduous process of L2 learning, an issue that will be the focus of the following subsection.

\section{L2 Grit}

Anecdotally, grit constitutes one of the characteristics of good language learners who need particularly large amounts of sustained effort to optimize their work and for whom uncertainty and difficulty must be the driving forces pushing them to proceed towards higher levels of attainment with an indomitable spirit (Yamashita, 2018). However, studies delving into grit experienced by L2 learners are still few and far between. This can be attributed to the fact that no language-specific grit scale was available until quite recently, meaning that SLA researchers were confined to merely adapting the aforementioned domain-general inventories, that is, Grit-O, and Grit-S (Duckworth et al., 2007; Duckworth \& Quinn, 2009) for speakers of languages other than English (e.g., German, Danish, Russian, Turkish, Korean, Japanese). This inevitably entailed the danger of less precise, out-of-context measurement of grit that could not appropriately address the uniqueness of the L2 learning process (Teimouri et al., 2020). The empirical investigations of grit in L2 learning are briefly overviewed below.

\section{Domain-general research into L2 grit}

This section reports a handful of L2 grit-related quantitative studies using the domain-general, Grit-O, and Grit-S scales (Duckworth et al., 2007; Duckworth \& Quinn, 2009). They were conducted in different learning environments with the purpose of examining the relationship between this personality trait and other ID factors, that is, curiosity, enjoyment, willingness to communicate (WTC), motivation and foreign language classroom anxiety.

The aim of Lake's (2013) study involving 539 first- and second-year Japanese female students representing different majors was to investigate the relationships among global positive psychology concepts, motivational concepts, positive L2 self-variables and TL proficiency. The analysis of the data gathered by means of the Grit-O Scale (Duckworth et al., 2007), the Curiosity and Exploration Inventory-II (Kashdan et al., 2009), positive L2 self- measures and L2 motivational measures demonstrated that grittier students were more willing to invest their time and energy in learning the English language and to display higher levels of curiosity, hope, subjective happiness and flourishing.

In their research project carried out among 183 Indian high- and low-achieving students, Changlek and Palanukulwong (2015) investigated the connections between the participants' experience of grit, motivation, anxiety and English language achievement. Using modified versions of the Language Learning Orientation Scale (Noels et al., 2000) and the Foreign Language Classroom Anxiety Scale (Horwitz et al., 1986), the Grit-S Scale (Duckworth \& Quinn, 2009) as well as the respondents' 5semester English language GPA, the researchers revealed that high-achievers' motivation and grit were significantly, positively associated, whereas anxiety and grit were shown to be significantly, negatively correlated. A different tendency was detected with respect to low-achievers whose motivation was significantly and positively linked to anxiety. The most conspicuous determinants of language achievement for both groups of respondents comprised negative evaluation, intrinsic motivation and test anxiety.

Wei et al. (2019) sought to examine the link between grit and 832 Chinese middle school students' foreign language performance (FLP) as well as the mediating effect of foreign language enjoyment (FLE) and classroom environment (CE). The analysis of the data that were collected by means of the Grit-S Scale (Duckworth \& Quinn, 2009), the Chinese version (Li et al., 2018) of the FLE Scale (Dewaele \& MacIntyre, 2016), and the English Classroom Environment Inventory (Liu \& Liu, 2010) revealed a significant positive, FLE- and CE-mediated connection between participants' grit and their FLP. Additionally, CE was found to moderate the association between grit and FLE.

Lee (2020) looked into the connections between grit, enjoyment and WTC, as experienced by 647 Korean English as a foreign language (EFL) middle school, high school and university students. The data were obtained from a four-part questionnaire utilizing five items tapping into L2 WTC (Lee \& Lee, 2019), ten items of the Grit-O Scale (Duckworth et al., 2007) and six items adapted from the Foreign Language Enjoyment (FLE) scale (Dewaele \& MacIntyre, 2014) as well as from two dimensions of FLE (FLE-Teacher and FLE-atmosphere) (Li et al., 2018). The 
analysis allowed for identification of such paths to fostering L2 WTC as encouraging students to persevere in attempting to initiate English communication and creating conditions favorable to a positive classroom climate.

It is also worth briefly describing Khajavy et al.'s (2020) study carried out among 1224 Iranian EFL university students with a few purposes in mind, namely: to identify the most suitable factor structure for grit and language mindset, to examine possible gender differences in grit and language mindset, to investigate the association between grit and language mindset, and to determine the extent to which grit and language mindset predict L2 achievement. The analysis of the data obtained from a questionnaire drawing on Lou and Noels' (2017) language mindset inventory, Duckworth et al.'s (2007) Grit-O Scale and the participants' course grades demonstrated that there were no significant gender differences for grit and language mindset. Concurrently, a growth language mindset was found to positively, albeit weakly, predict the PE component of grit, whereas a fixed language mindset was reported to negatively predict the CI subconstruct of grit. One more finding was that the two-factor structure for both grit and language mindset constituted a better fit for the data than the single-factor structure and that only a growth language mindset positively but weakly predicted L2 achievement. Finally and most interestingly, the results highlighted that grit did not seem to be of much relevance in the face of easy and ill-defined tasks.

\section{Domain-specific research into L2 grit}

Searching for the ways of avoiding global-local inconsistencies that accompanied past personality-focused SLA research, Teimouri et al. (2020) developed and validated the nine-item L2-Grit Scale which, similarly to the domain-general scales (Duckworth et al., 2007; Duckworth \& Quinn, 2009), consists of the perseverance-of-effort (5 items) and the consistency-of-interest (4 items) dimensions. This new, language-specific scale was used in their study with the aim of investigating the extent to which grit was connected to motivational behaviors and language achievement of 191 EFL students. The findings revealed a positive correlation between language-specific grit and participants' L2 learning motivation. Moreover, L2 grit was shown to be more strongly related to motivational factors and L2 achievement than domain-general grit.
One more study that took a domain-specific perspective on grit was carried out by Sudina and Plonsky (2020) among 153 Russian undergraduates who were students of different additional languages. Its aim was to examine possible links between L2 grit and L2/L3 proficiency, achievement and anxiety. Quantitative data analysis indicated that L2 grit was found to be negatively associated with anxiety and to exhibit stronger predictive validity than domain-general grit. The findings enabled the researchers to offer support for a two-dimensional factor structure of L2 grit and its reconceptualization as a language-domain-specific variable in the L2 learning process, thus to some extent addressing the reservations discussed earlier in the present paper.

Considering the importance of contextual variation of personality traits in SLA, we follow the nascent line of research and thus adopt the language-domain approach to examining L2 grit. In addition, we look into the role of this variable on the basis of both quantitative and qualitative data. To the best of our knowledge, this is one of the first studies to address grit in the Polish educational context. Thus, it seeks to fill an important gap in existing research, adding to our understanding of the role of grit in various instructional settings and in different types of L2 programs.

\section{METHOD}

\section{Aims and Research Questions}

The study was conducted with the purpose of investigating grit in the Polish educational context, focusing on a very distinctive group of learners, that is, university students majoring in English, who are expected to attain a high level of proficiency in English to be able to work successfully as teachers, translators, interpreters, business assistants, etc. The following research questions (RQs) were addressed:

RQ1: What is the level of L2 grit experienced by the Polish university students of English?

RQ2: Are there any differences in this respect between 1st-, 2nd-, and 3rd-year students?

RQ3: What are the dynamics of grit in learning English as a foreign language and how is it manifested by the participants? 


\section{Participants}

The participants were 99 Polish university students (71 females and 28 males) majoring in English, enrolled in the first, second and third year of a three-year BA program. On average, they were $21.89(S D=2.91)$ years of age and their mean experience in learning English equaled 11.34 ( $S D=$ $4.45)$ years. When it comes to the participants' mastery of the target language (TL), it was gauged in a more objective and a more subjective manner alike. Taking into account the grading system applied in institutions of higher education in Poland, the students' average grade for the comprehensive end-of-the-year examination in English, comprising both oral and written components, amounted to $3.87(S D=0.62)$ on the scale of 2 (fail) to 5 (very good) but their selfevaluation was slightly lower and equaled $3.67(S D=0.55)$ on the same scale. The BA program the students attended included an intensive course in English, that is, classes related to language skills and subsystems, as well as a number of content courses, electives and seminars (e.g., in linguistics, British and American history and literature, foreign language teaching methodology). Most of the classes were taught in English. As one of the major graduation requirements, in the last year the students had to write a diploma paper in the English language in a chosen content area in the final year of the study. It should also be noted that, as is typical of contexts such as the one in Poland, participants had rare opportunities for using the TL outside of school. Such access was in the main confined to online resources and seldom involved face-to-face or even online interactions with native speakers or other proficient users of the TL.

\section{Data Collection}

In order to collect the requisite data, both quantitative and qualitative research instruments were utilized. They were as follows:

- A background questionnaire - this tool comprised items related to demographic information concerning the participants, such as their sex, age, year of study, the length of English study, the end-of-the-year examination grade in English, self-evaluation of English proficiency, and out-of-school contact with the target language;

- The Language-Domain Grit Scale (L2 grit) the instrument was developed and tested by Teimouri et al. (2020) and contains nine 5point Likert scale items ( 1 - strongly disagree, 5 - strongly agree) related to perseverance of effort in language learning (five items) and consistency of interest (four items), that is, the two distinct sub-components of the construct under investigation (Duckworth et al., 2007);

- Semi-structured interviews - these were conducted with 12 volunteers in a quiet room and audio-recorded; the interviewees were asked the following questions which were further elaborated upon, depending on the responses:

- What are your current aims for learning English and are they different from the ones in the past?

- What are your weak points in learning English?

- Are you doing anything to overcome them?

- Has your determination in learning English changed in the process of learning this language (e.g., was it stronger/weaker at high school level)?,

- As far as you are concerned, can you observe any differences in the way you learned English at high school and university levels?

In order to minimize the danger of misinterpretation or misunderstanding, the background questionnaire as well as the L2 grit scale were worded in Polish, which was the participants' mother tongue. The instruments were administered in a paper-and-pencil version and completed anonymously by the students in class. For reasons expounded above, the interviews were also carried out in the Polish language, although the students were offered an option to provide responses in the TL. 


\section{Data Analysis}

The collected data were subjected to quantitative and qualitative analysis. The quantitative analysis involved both descriptive and inferential statistics. The former comprised calculating mean and standard deviation values for the scale and subscales, and the latter encompassed one-way ANOVA in order to tease out differences among students at different levels of the program. It should be added that before the analysis, all the negatively keyed items in the Language-Domain Grit scale were reverse-coded. The significance value was set at $p<.05$ for the analysis and the effect size was interpreted in accordance with the guidelines offered by Dörnyei (2007, p. 217). As far as the qualitative analysis is concerned, it encompassed four stages outlined by Dörnyei (2007), that is, (1) pre-coding, (2) initial coding, (3) second level coding, and (4) final coding. The partially transcribed data (Dörnyei, 2007) were first thoroughly read in order to obtain a better picture of the available information (stage one) and then read and read again with the purpose of finding some regularly occurring issues for which labels were produced and codes were suitably termed (stage two). This, in turn, allowed an accurate recoding of code properties. Stage three involved the organization of the data into novel broad categories by means of grouping some comparable categories formed in the preceding stage, or to develop a new one, if no matches were uncovered. Finally, the categorized data were examined anew and the existing categories were rereviewed to accommodate new insights (stage four). The credibility of the categories was then verified by another researcher. The whole procedure generated a satisfactory interrater reliability of $92 \%$.

\section{RESULTS}

\section{Quantitative Data}

As can be seen in Table 1, which includes the mean and standard deviation values for the first-, second-, and thirdyear students as well as in Figure 1, which graphically represents the mean year-to-year changes, overall, the younger participants turned out to be grittier than their older counterparts (i.e., the first-year students were grittier in learning English than the second- and third-year ones and the second-year learners were grittier than the third-year subjects). It should be noted, however, that the differences in the means were small (i.e., they equaled 0.21 between the first- and the second-year students, 0.43 between the firstand the third-year learners and 0.22 between the secondand the third-year subjects) and not statistically significant $(p>.05)$. The participants could be described as relatively gritty in view of the fact that the general mean for L2 grit oscillated between 3.83 in year 1 and 3.40 in year 3, with the average of 3.63 , which can be considered as fairly high. The analysis of the data also revealed that the means for some of the items approached or even exceeded the value of 4, which, given the 5-point Likert scale adopted for the study, can be regarded as a sign of high levels of grit.

Table 1. Mean and Standard Deviation Values for the First-, the Second-, and Third-Year Students

\begin{tabular}{lccc}
\hline $\begin{array}{l}\text { Year of } \\
\text { study }\end{array}$ & & $M$ & $S D$ \\
\hline \multirow{3}{*}{ Year 1 } & L2 grit & 3.83 & .41 \\
& Perseverance of effort & 3.68 & .64 \\
& Consistency of interest & 4.03 & .65 \\
\cline { 2 - 4 } Year 2 & L2 grit & 3.62 & .71 \\
& Perseverance of effort & 3.74 & .64 \\
& Consistency of interest & 3.48 & .98 \\
\cline { 2 - 4 } Year 3 & L2 grit & 3.40 & .70 \\
& Perseverance of effort & 3.53 & .51 \\
& Consistency of interest & 3.24 & 1.14 \\
\cline { 2 - 4 } Overall & L2 grit & 3.63 & .65 \\
& Perseverance of effort & 3.67 & .61 \\
& Consistency of interest & 3.58 & .98 \\
\hline
\end{tabular}

As far as the differences in the means between the two sub-components of the L2 grit scale (i.e., perseverance of effort and consistency of interest) are concerned, the analysis of the data demonstrated that the second- and the third-year students manifested the most and the least perseverance of effort in learning English, respectively. The differences in the means among the three groups of participants were small (i.e., the difference between the first- and the second-year students equaled 0.06 , the difference between the first- and the third-year learners amounted to 0.15 and the difference between the secondand the third-year subjects was tantamount to 0.21 ) and they did not reach statistical significance $(p>.05)$.

As regards the second sub-component of the investigated construct, that is, consistency of interest in learning English, 
the analysis of the gathered data showed that the first- and the third-year students turned out to demonstrate the most and the least consistency of interest in learning the target language, respectively. The differences in the means between the groups were in some cases fairly substantial and equaled 0.55 between the first- and the second-year students, 0.79 between the first- and the third-year learners and 0.24 between the second- and the third-year subjects. One-way ANOVA revealed statistically significant differences among the groups $(F(2.96)=5.039, p=.008, \eta 2$ $=.09$ ). In addition, post hoc tests using the Bonferroni correction showed statistically significant differences between Year 1 and Year 2 as well as Year 1 and Year 3 ( $p$ $=.047$ and $p=.010$, respectively). The $S D$ values were the highest for this component of L2 grit, irrespective of the year of study but also showing a tendency to increase with the passage of time, which may speak to the considerable impact of individual variation in this respect.

Figure 1. L2 Grit Levels For First-, Second-, and Third-Year Students

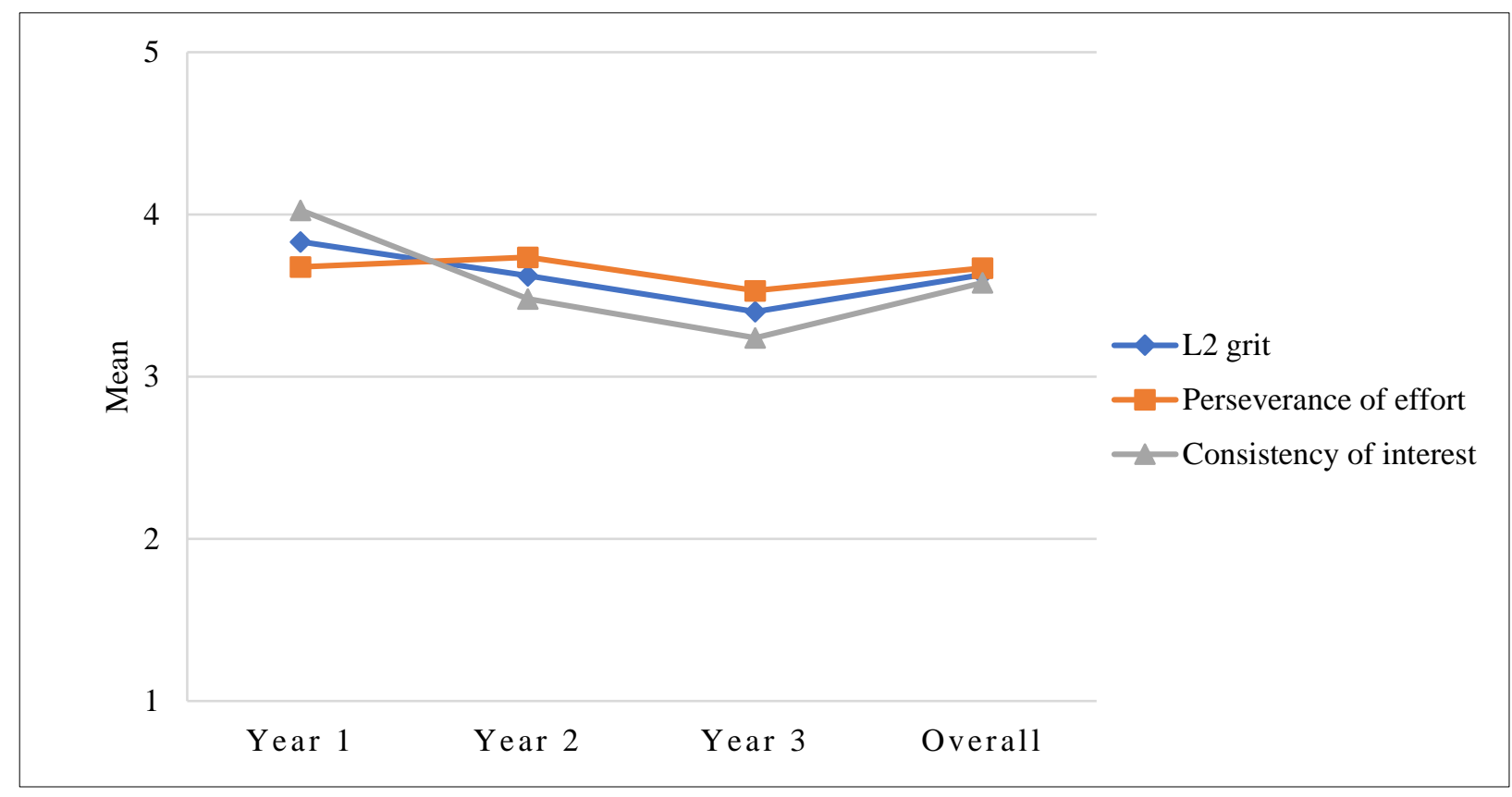

\section{Qualitative Analysis}

The qualitative analysis of the data collected by means of the semi-structured interviews yielded the following two broad categories: (1) the identification of weaknesses in learning English and attempts to eliminate the weak points, and (2) the dynamicity of grit in learning the target language.

With respect to the first category, the analysis revealed that all the interviewees were aware of their weaknesses in the knowledge of English as well as learning this TL. The participants most frequently attributed them to various gaps in their knowledge of the systems and subsystems of the target language, such as, grammar, vocabulary, pronunciation, reading and listening as well as ascribing them to the lack of systematicity or a certain degree of sluggishness in learning English. However, the interviewees were determined to work on and eliminate the identified weaknesses. For example, individual students endeavored to do more exercises with the purpose of addressing the problematic areas, they tried to get in touch with English native speakers over the Internet, they attempted to learn English by playing computer games, or set aside some time in order to complete certain language tasks. Several students also indicated that they plan their work and collaborate with their friends and/or colleagues from the group (or from work). These types of issues are shown in the following excerpts ${ }^{1}$ : 
- Lack of systematicity. Yes, I try to regularly repeat the material and speak in English more often / participate in situations where its use is necessary.

- I'm weak at grammar, but still trying to learn it. I practice it myself by solving various grammar exercises.

- Vocabulary. I make flashcards, learn from them, try to read books in English, watch movies / series with English subtitles.

- I am a slow learner and it takes me a long time to learn ... I plan my activities and set the time to complete certain exercises. I have a list of things to do ... I cross them out when something is done.

- I speak to native speakers via Skype.

As regards the second category, that is, the dynamicity of grit in learning the target language, qualitative analysis revealed that $\mathrm{L} 2$ grit is not a permanent construct but it can change over time. Overall, the interviewees were not highly determined to learn the English language at elementary or high school levels but their level of grit increased when they had started to study the targeted language at the university. However, the issue concerning the intensity of the investigated construct was of an individual nature. For example, one interviewee was less determined to learn English in high school than when she started her English studies. The reason for this was the fact that learning English at school was not particularly demanding since it was mainly based on the textbook ("at school it was booklike"), while the university classes turned out to be more demanding for her ("there is more to study and it is not that simple," "the more I know, the more I see that I know less"). Another interviewee described herself as a very determined person in learning English at school and at the beginning of her studies but whose L2 grit began to decline during her studies at university only to increase again towards the end of them ("At school I studied for myself . . . at the beginning of my studies at university too, but then just to pass the exams ... Now I'm determined again and I'm learning for myself and in order to pass everything"). For yet another person, the determination to learn English has clearly increased lately due to the upcoming exams and the need to write a BA paper ("the determination is definitely greater now ... exams and then the BA paper motivate me more").

The changes in the L2 grit were also accompanied by changes in the pursuit of the goals that the interviewees set for themselves during their language education. In the earlier stages of learning the TL, the participants mainly aimed at general development of English skills, in particular those related to communication needs, while over time, or, more precisely, during the course of their studies, the students who participated in the interview began to notice the need for a more thorough knowledge of the English language (e.g., grammar, vocabulary), increased fluency in using it in communication, or they linked the good command of English with future professional work. Such tendencies can be seen in the following excerpts:

- Now not only do I want to speak this language but I want to be able to say that I know the language very well and that I will be able to speak with a native speaker with confidence.

- Previously I wanted to develop communication skills, not for professional purposes . . now these are professional issues.

- After the first year I put more emphasis on grammar because that is my Achilles' heel.

- Earlier I was afraid to speak because I knew I couldn't . . . now I can't either but I know I have to speak to improve this skill ... whether with errors or without if I don't talk, I won't progress.

\section{DISCUSSION}

The present study aimed to address three research questions which concerned the level of grit experienced by Polish university students majoring in English (RQ1), the differences in this respect between students at different stages of the program (i.e., year 1, 2 and 3) (RQ2), as well as the ways in which grit is subject to variation over time (RQ3). Given the focus of the present study and the distinctive group of participants it involved, it is certainly not straightforward to link the discussion to previous research findings, although such attempts are made whenever deemed appropriate or necessary. 
When it comes to RQ1, it is clear that the participants manifest a considerable level of grit, as evidenced by the overall mean of 3.63 on a 5-point Likert scale. Such findings can hardly be seen as surprising, given that they were English majors who had made a conscious decision to get to know the various intricacies of that language in order to achieve a high level of proficiency which would enable them to use the TL for professional purposes in the future. To use the metaphor offered by Duckworth et al. (2007), by choosing this particular program they embarked on a marathon of mastering English, thereby embracing the disappointments and failures that this process somewhat inevitably involved. Moreover, when we consider the fact that in order to continue in the program English majors have to manifest superior command of all TL skills and subsystems, with their achievement being verified both on a regular basis in the different components of the intensive English course and by means of an extremely challenging end-of-the-year examinations, the results are also indirectly in line with the empirical evidence indicating the link between grit and L2 attainment (e.g., Lake, 2013; Teimouri et al., 2020; Wei et al., 2019). At the same time, only minute differences were revealed with respect to the importance of the two subcomponents of the construct of grit, that is, perseverance of effort and consistency of interest (i.e., 3.67 vs. 3.58 , respectively), which indicates that both of them play a crucial role in shaping English majors' dedication to the study of the TL. This might be interpreted as meaning that Credé et al.'s (2017) concerns about the internal structure of grit as hinging more on PE than CI might not be relevant in the context in which the study was conducted, or that the importance of the two subcomponents might be accentuated to a greater or lesser extent at different stages of the learning process. In other words, it would seem that in the case of English majors, the desire to study the TL against all potential odds is rooted in pretty much equal measure both in their need to persevere in learning English despite all the experienced problems and difficulties, as well as unwavering interest in this language but also perhaps the broadly conceived culture that it represents. An important caveat, however, is that interest in the TL is not always tantamount to interest in the contents of the program that the students attend.

With respect to RQ2, even though the differences between year 1, year 2 and year 3 failed to reach statistical significance, the analysis of the data showed a downward trend in the overall level of grit over time. The situation is much more complicated, however, when we examine the ways in which the importance of the subcomponents of grit changed at different levels of the BA program. No significant differences were revealed for perseverance of effort, although we should still note a slight increase from year 1 to year 2 and then a slight decrease in year 3. When it comes to consistency of interest, a clear decrease can be seen with the passage of time, as evidenced by the statistically significant differences between the three cohorts, that is, the students in the three levels of the BA program. The interpretation of such findings is not really possible with recourse to previous empirical investigations which did not really look into how grit changes for learners at different stages of their efforts to learn an L2 and certainly not for English majors. Therefore, it makes much more sense to expound the results basing on the specificity of the program the participants followed as well as the present authors' experience with it. For one thing, it would seem that many high school graduates willing to study English philology are not fully aware of what the program really entails, being convinced that it is in the main focused on the development of TL proficiency. However, when they are confronted with the requirement to attend courses in linguistics, history, literature or language teaching methodology, which are also taught in English, many students begin to struggle to meet such challenges. On the one hand, this could have resulted in a rise in the intensity of invested effort in year 2 and, although the change in sheer numbers was not significant, the comments in the interviews clearly showed that the students did their utmost to deal with their weak points with respect to the mastery of the TL, resorting to metacognitive, cognitive and social strategies for this purpose, which could of course perform several functions simultaneously depending on the nature of the challenge (cf. Oxford, 2017).

On the other hand, this could have also led to a considerable drop in consistency of interest in the content to be learned that might have little intrinsic appeal but needs to be mastered to successfully meet the requirements of the program. This result testifies to a kind of conflict between what is indeed engaging and what has just to be done to graduate, which can explain the differential role of the subcomponents of grit in the course of time. In other words, while the students know that their ultimate success hinges upon their ability and willingness to grin and bear it, this is 
not accompanied by interest in all the components of the program. Certainly noteworthy is the fact that the consistency of interest was subject to greatest individual variation, irrespective of the year of study but also with a clear trend to increase with time. This might indicate that this aspect of grit might be mediated by a host of individual difference factors (e.g., motivation, however it might be defined, willingness to communicate, learning styles and strategies or personality) but also by the students' range of interests because while some of them might be eager to get to know more about linguistics or L2 teaching, others might be more willing to find out about culture, history or literature, a situation that can be attributed to the decision they make with respect to the topic of their diploma paper and the area to be covered in their final exam as a prerequisite to graduating.

Finally, in relation to RQ3, it can be addressed on the basis of both the quantitative and qualitative data collected for the purpose of the study. On the one hand, it is clear that the level of grit as well as its two subcomponents is likely to fluctuate over the course of time, in this case from one year of the BA program to the next, for the reasons which have been elucidated above. On the other hand, the participants' responses to the interview questions also demonstrated that grit is inherently subject to change over longer periods of time, both from high school to university or at a particular level of the BA program, with the nature of learning goals playing an important role in this respect. To be more specific, when some of the students entered the program, their level of grit increased in order to be able to face the new challenges and to be better able to deal with the demands of instruction that were quite different from those faced in high school. Some of them, however, later experienced a drop in grit, which can perhaps be attributed to much less consistency of interest which, as mentioned above, could likely be connected to the need to study things that they found unappealing or perhaps even unrelated to the goal of achieving a high level of TL proficiency, such as phonology, syntax, literature, history or issues related to L2 teaching and learning. After all, the analysis of the interview data did not yield any references to specific objectives in these areas, quite in contrast to language-related issues which were always clearly in focus. Then again, at least some of the students reported even greater perseverance when the goals became more crystalized in the last year of study, when the energy could be channeled into specific domains that they had been able to choose, such as writing a diploma paper in a particular area (e.g., linguistics, culture, methodology) or focusing on electives that were more in line with their aspirations. It would thus seem that the two subcomponents of grit might trump each other at different stages of education, with perseverance of effort coming into play in order to facilitate survival in a highly demanding program and consistency of interest gaining in importance when the students were given a choice as to what they were learning. If we link this assumption to some of the previous research, it could by hypothesized, for example, that classroom enjoyment is more likely to mediate grit only for some learners, in some programs and only in some specific learning situations (cf. Wei et al, 2019).

The present study is certainly not free from limitations. First, the results have to be taken with considerable circumspection because grit was compared among students at different levels of the BA program cross-sectionally rather than in a longitudinal manner. In other words, we did not trace the development of this ID factor over time with the same group of individuals but, rather, examined it with students enrolled in different levels of the program. Even though this allowed some valuable insights into the factors shaping grit, this could be mainly done only with respect to the changing circumstances and demands rather than the challenges a given individual needed to face. Second, the number of participants in the quantitative part of the study was quite small, which may have impacted the results of the numerical analysis. Third, the investigation did not take into account other individual difference factors that might have influenced grit, whatever its subcomponent (e.g., motivation, willingness to communicate, personality, anxiety, curiosity) and it also failed to factor in the participants' TL proficiency, whether more objective or self-reported. It is clear that such vital issues will need to be given careful consideration in future empirical investigations.

\section{CONCLUSION}

Grit is without doubt an important ID factor which merits careful investigation in the field of SLA, irrespective of the criticisms that may have been leveled at its internal structure or the extent to which it might be partly subsumed in other constructs that have been examined by researchers, particularly in the field of educational psychology (cf. 
Credé et al., 2017; Datu et al. 2016). The study reported in this paper has provided another piece of the puzzle concerning the role of grit in different situations in which additional languages are learned and taught, in this case with respect to English majors who are expected to attain a high level of TL proficiency to be able to function effectively in different walks of professional life. The importance of this empirical investigation also lies in the fact that it is among the first in the Polish educational context and that it has used a domain-specific L2 grit scale which appears to be a more appropriate tool in such contexts than domain-general scales (cf. Teimouri et al., 2020). This said, there is an urgent need for further research into the contribution of L2 grit, such that would be more longitudinal in nature, take into consideration the mediating role of other ID factors, and also determine the effects of this construct on different aspects of TL proficiency. Since we do know that individual variation plays a huge role in both the process and product of L2 learning, it seems only logical to offer further evidence for how grit fits into the picture, whether on its own or in combination with other ID factors.

\section{Author Contributions}

All authors have materially participated in the research and article preparation. Additionally, all authors have approved the final version of the article.

\section{Funding}

The authors received no financial support for this work.

\section{REFERENCES}

Changlek, A., \& Palanukulwong, T. (2015). Motivation and grit: Predictors of language learning achievement. Veridian E-Journal, 8(4), 23-38.

Costa, P. T., \& McCrae, R. R. (1992). Revised NEO Personality Inventory (NEO-PI-R) and NEO FiveFactor Inventory (NEO-FFI) Professional Manual. Psychological Assessment Resources.

Cox, C. M. (1926). Genetic studies of genius: Vol. 2: The early mental traits of three hundred geniuses. Stanford University Press.

Credé, M. (2018). What shall we do about grit? A critical review of what we know and what we don't know. Educational Researcher, 47(9), 606-611. https://doi.org/10.3102/0013189X18801322

Credé, M., Tynan, M. C., \& Harms, P. D. (2017). Much ado about grit: A meta-analytic synthesis of the grit literature. Journal of Personality and. Social Psychology, 113(3), 492-511. https://doi.org/10.1037/pspp0000102

Datu, J. A. D., Valdez, J. P. M., \& King, R. B. (2016). The successful life of gritty students: Grit leads to optimal educational and well-being outcomes in a collectivist context. In R. B. King \& B. I. Bernardo (Eds.), The psychology of Asian learners (pp. 503-516). Springer.

De Fruyt, F., Van De Wiele, L., \& Van Heeringen, C. (2000). Cloninger's psychobiological model of temperament and character and the five-factor model of personality. Personality and Individual Differences, 29, 441-452. https://doi.org/10.1016/S0191-8869(99)00204-4

Dewaele, J.-M. (2014). It takes two to tango: The dynamic interaction of emotional and psychological aspects in foreign language learning. ETAS Journal. The Magazine for English Professionals, 31(2), 51-53.

Dewaele, J. M., \& MacIntyre, P. D. (2016). Foreign language enjoyment and anxiety: The right and left feet of the language learner. In T. Gregersen, P. D. MacIntyre, \& S. Mercer (Eds.), Positive psychology in SLA (pp. 215-236). Multilingual Matters.

Dörnyei, Z. (2005). The psychology of the language learner: Individual differences in second language acquisition. Lawrence Erlbaum. 
Dörnyei, Z. (2007). Research methods in applied linguistics. Oxford University Press.

Dörnyei, Z., \& Ryan, S. (2015). The psychology of the language learner revisited. Routledge.

Duckworth, A. L., Kirby, T. A., Tsukayama, E., Berstein, H., \& Ericsson, K. A. (2011). Deliberate practice spells success: Why grittier competitors triumph at the National Spelling Bee. Social Psychological and Personality Science, 2(2), 174-181. https://doi.org/10.1177/1948550610385872

Duckworth, A. L., Peterson, C., Matthews, M. D., \& Kelly, D. R. (2007). Grit: Perseverance and passion for long term goals. Journal of Personality and Social Psychology, 92(6), 1087-1101. https://doi.org/10.1037/0022-3514.92.6.1087

Duckworth, A. L., \& Quinn, P. D., (2009). Development and validation of the Short Grit Scale (Grit-S). Journal of Personality Assessment, 91(2), 166174. https://doi.org/10.1080/00223890802634290

Dweck, C. S. (2006). Mindset: The new psychology of success. Ballantine Books.

Eisenberger, R. (1992). Learned industriousness. Psychological Review, 99(2), 248-267. https://doi.org/10.1037/0033-295X.99.2.248

Ericsson, K. A., \& Charness, N. (1994). Expert performance: Its structure and acquisition. American Psychologist, 49, 725-747. https://doi.org/10.1037/0003-066X.49.8.725

Eskreis-Winkler, L., Duckworth, A. L., Shulman, E. P., \& Beal, S. (2014). The grit effect: Predicting retention in the military, the workplace, school and marriage. Frontiers in Psychology, 5(36). https://doi.org/10.3389/fpsyg.2014.00036

Galton, F. (1892). Hereditary genius: An inquiry into its laws and consequences. Macmillan.

Georgoulas-Sherry, V., \& Kelly, D. R. (2019). Resilience, grit, and hardiness: Determining the relationships amongst these constructs through structural equation modeling techniques. Journal of Positive Psychology \& Wellbeing, 3(2), 165-178.
Hakuta, K., Butler, Y. G., \& Witt, D. (2000). How long does it take English language learners to develop oral proficiency and academic proficiency in English? University of California Linguistic Minority Research Institute.

Heckman, J. J., \& Mosso, S. (2014). The economics of human development and social mobility. Annual Review of Economics, 6(1), 689-733. https://doi.org/10.1146/annureveconomics$\underline{080213-040753}$

Horwitz, E. K. (2001). Language anxiety and achievement. Annual Review of Applied Linguistics, 21, 112126. https://doi.org/10.1017/S0267190501000071

Horwitz, E. K., Horwitz, M., \& Cope, J. (1986). Foreign language classroom anxiety. The Modern Language Journal, 70(1), 125-132. https://doi.org/10.1111/j.15404781.1986.tb05256.x

Howe, M. J. A. (1999). Genius explained. Cambridge University Press.

Hwang, M. H., Lim, H. J., \& Ha, H. S. (2017). Effects of grit on the academic success of adult female students at Korean Open University. Psychological Reports, 121, 705-725. https://doi.org/10.1177/0033294117734834

James, W. (1907). The energies of men. Science, 25, 321332.

Kashdan, T. B., Gallagher, M. W., Silvia, P. J., Winterstein, B. P., Breen, W. E., Terhar, D., \& Steger, M. F. (2009). The curiosity and exploration inventory-II: Development, factor structure, and psychometrics. Journal of Research in Personality, 43(6), 987-998. https://doi.org/10.1016/j.jrp.2009.04.011

Keegan, K. (2017). Identifying and building grit in language learners. English Teaching Forum, 55(3), 2-9.

Khajavy, G. H., MacIntyre, P. M., \& Hariri, J. (2020). A closer look at grit and language mindset as predictors of foreign language achievement. Studies in Second Language Acquisition, 43(2), 
379-402.

https://doi.org/10.1017/S0272263120000480

Kramer, B., McLean, S., \& Martin, E. S. (2018). Student grittiness: A pilot study investigating scholarly persistence in EFL classrooms. Osaka Jogakuin Junior College Kiyo, 47, 25-41.

Lake, J. (2013). Positive L2 self: Linking positive psychology with L2 motivation. In M. T. Apple, D. Da Silva, \& T. Fellner (Eds.), Language learning motivation in Japan (pp. 225-244). Multilingual Matters.

Lee, J. S., \& Lee, K. (2019). Role of L2 motivational self system on willingness to communicate of Korean EFL university and secondary students. Journal of Psycholinguistic Research, 49, 147-161. https://doi.org/10.1007/s10936-019-09675-6

Lee, J. S. (2020). The role of grit and classroom enjoyment in EFL learners' willingness to communicate. Journal of Multilingual and Multicultural Development. Advance online publication. https://doi.org/10.1080/01434632.2020.1746319

Li, C., Jiang, G., \& Dewaele, J.-M. (2018). Understanding Chinese high school student' foreign language enjoyment: Validation of the Chinese version of the foreign language enjoyment scale. System, 76, 183-196.

https://doi.org/10.1016/j.system.2018.06.004

Li, S. (2016). The construct validity of language aptitude:

A meta-analysis. Studies in Second Language Acquisition, 38(4), 801-842.

https://doi.org/10.1017/S027226311500042X

Liu, L., \& Liu, Y. (2010). The making of the English classroom environment inventory and its application [Chinese]. Foreign Language Learning Theory and Practice, 14, 71-78.

Lou, N. M., \& Noels, K. A. (2017). Measuring language mindsets and modeling their relations with goal orientations and emotional and behavioral responses in failure situations. The Modern Language Journal, 101(1), 214-243. https://doi.org/10.1111/modl.12380
MacIntyre, P. D., \& Gregersen, T. (2012). Emotions that facilitate language learning: The positivebroadening power of the imagination. Studies in Second Language Learning and Teaching, 2(2), 193-213. https://doi.org/10.14746/ssllt.2012.2.2.4

MacIntyre, P. D., Gregersen, T., \& Mercer, S. (Eds.) (2016). Positive psychology in SLA. Multilingual Matters.

Masgoret, A. M., \& Gardner, R. C. (2003). Attitudes, motivation, and second language learning: A meta-analysis of studies conducted by Gardner and associates. Language Learning, 53(1), 123-163. https://doi.org/10.1111/1467-9922.00212

Noels, K. A., Pelletier, L. G., Clement, R., \& Vallerand, R. J. (2000). Why are you learning a second language? Motivational orientations and selfdetermination theory. Language Learning, 50(1), 57-85. https://doi.org/10.1111/0023-8333.00111

Oxford, R. L. (2015). Emotion as the amplifier and the primary motive: Some theories of emotion with relevance to language learning. Studies in Second Language Learning and Teaching, 5(3), 371-393. https://doi.org/10.14746/ssllt.2015.5.3.2

Oxford, R. L. (2017). Teaching and researching language learning strategies: Self-regulation in context. Routledge.

Pawlak, M. (2011). Anxiety as a factor influencing the use of language learning strategies. In M. Pawlak (Ed.), Extending the boundaries of research on second language learning and teaching (pp. 149165). Springer.

Pawlak, M. (2017). Overview of learner individual differences and their mediating effects on the process and outcome of interaction. In L. Gurzynski-Weiss (Ed.), Expanding individual difference research in the interaction approach: Investigating learners, instructors, and other interlocutors (pp. 19-40). John Benjamins.

Pawlak, M. (2020). Individual differences and good language teachers. In C. Griffiths \& Z. Tajeddin (Eds.), Lessons from good language teachers (pp. 121-132). Cambridge University Press. 
Perkins-Gough, D. (2013). The significance of grit: A conversation with Angela Lee Duckworth. Educational Leadership, 71, 14-20.

Roberts, B. W., Chernyshenko, O. S., Stark, S., \& Goldberg, L. R. (2005). The structure of conscientiousness: An empirical investigation based on seven major personality questionnaires. Personnel Psychology, 58, 103-139. https://doi.org/10.1111/j.1744-6570.2005.00301.x

Roberts, Y. (2009). Grit: The skills for success and how they are grown. The Young Foundation.

Shechtman, N., DeBarger, A. H., Dornsife, C., Rosier, S., \& Yarnall, L. (2013). Promoting grit, Tenacity, and perseverance: Critical factors for success in the 21st century. U.S. Department of Education, Office of Education Technology. Retrieved from http://pgbovine.net/OET-Draft-Grit-Report-2-1713.pdf

Seligman, M. E. P. (2003). Positive psychology: Fundamental assumptions [Editorial]. The Psychologist, 16(3), 126-127.

Seligman, M. E. P., \& Csikszentmihalyi, M. (2000). Positive psychology: An introduction. American Psychologist, 55(1), 5-14. https://doi.org/10.1037/0003-066X.55.1.5

Sudina, E., \& Plonsky, L. (2021). Language learning grit, achievement, and anxiety among L2 and L3 learners in Russia. International Journal of Applied Linguistics, 172(2), 161-198. https://doi.org/10.1075/itl.20001.sud

Teimouri, Y., Plonsky, L., \& Tabandeh, F. (2020). L2 Grit: Passion and perseverance for second-language learning. Language Teaching Research. Advance online publication.

https://doi.org/10.1177/1362168820921895

Tough, P. (2011, September). What if the secret to success is failure? The New York Magazine, 14, 1-12.

Tough, P. (2012). How children succeed: Grit, curiosity, and the hidden power of character. Houghton Mifflin.

Von Culin, K. R., Tsukayama, E., \& Duckworth, A. L. (2014). Unpacking grit: Motivational correlates of perseverance and passion for long-term goals. The Journal of Positive Psychology, 9(4), 306-312. https://doi.org/10.1089/17439760.2014.898320

Wei, H., Gao, K.., \& Wang, W. (2019). Understanding the relationship between grit and foreign language performance among middle school Students: The roles of foreign language enjoyment and classroom environment. Frontiers in Psychology, 10,1-8. https://doi.org/10.3389/fpsyg.2019.01508

Wolters, C. A., \& Hussain, M. (2015). Investigating grit and its relations with college students' selfregulated learning and academic achievement. Metacognition and Learning, 10(3), 293-311. https://doi.org/10.1007/s11409-014-9128-9

Yamashita, T. (2018). Grit and second language acquisition: Can passion and perseverance predict performance in Japanese language learning? [Unpublished MA thesis]. University of Massachusetts. https://scholarworks.umass.edu/masters_theses_2/ $\underline{679}$

Zernike, K. (2016, February). Testing for joy and grit? Schools nationwide push to measure students' emotional skills. The New York Times, 29, 1-4. 